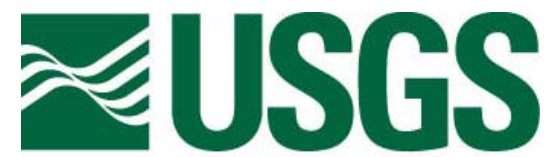

science for a changing world

\title{
Rotational Seismology: AGU Session, Working Group, and Website
}

By William H. K. Lee ${ }^{1}$, Heiner Igel ${ }^{2}$, Maria I.

Todorovska ${ }^{3}$, and John R. Evans ${ }^{1}$

Open-File Report 2007-1263

2007

U.S. Deprtment of the Interior

U.S. Geological Survey

${ }^{1}$ U.S. Geological Survey, Menlo Park, Calif.

2 University of Munich, Munich, Germany

${ }^{3}$ University of Southern California, Los Angels, Calif. 


\section{U.S. Department of the Interior DIRK KEMPTHORNE, Secretary}

\section{U.S. Geological Survey \\ Mark D. Myers, Director}

U.S. Geological Survey, Reston, Virginia 2007

For product and ordering information:

World Wide Web: http://www.usgs.gov/pubprod

Telephone: 1-888-ASK-USGS

For more information on the USGS - the Federal source for science about the Earth, its natural and living resources, natural hazards, and the environment: World Wide Web: http://www.usgs.gov

Telephone: 1-888-ASK-USGS

\section{Suggested citation:}

Lee, W.H.K., H. Igel, M.I. Todorovska, and J. R. Evans, 2007. Rotational Seismology: AGU Session, Working Group, and Website: U.S. Geological Survey Open-File Report 2007-1263, 7 p.

[http://pubs.usgs.gov/of/2007/1263/].

Any use of trade, product, or firm names is for descriptive purposes only and does not imply endorsement by the U.S. Government.

Although this report is in the public domain, permission must be secured from the individual copyright owners to reproduce any copyrighted material contained within this report. 


\section{Introduction}

Although effects of rotational motions due to earthquakes have long been observed (e. g., Mallet, 1862), nevertheless Richter (1958, p. 213) stated that: "Perfectly general motion would also involve rotations about three perpendicular axes, and three more instruments for these. Theory indicates, and observation confirms, that such rotations are negligible." However, Richter provided no references for this claim.

Seismology is based primarily on the observation and modeling of three-component translational ground motions. Nevertheless, theoretical seismologists (e.g., Aki and Richards, 1980, 2002) have argued for decades that the rotational part of ground motions should also be recorded. It is well known that standard seismometers are quite sensitive to rotations and therefore subject to rotation-induced errors. The paucity of observations of rotational motions is mainly the result of a lack, until recently, of affordable rotational sensors of sufficient resolution. Nevertheless, in the past decade, a number of authors have reported direct observations of rotational motions and rotations inferred from rigid-body rotations in short baseline accelerometer arrays, creating a burgeoning library of rotational data. For example, ring laser gyros in Germany and New Zealand have led to the first significant and consistent observations of rotational motions from distant earthquakes (Igel et al., 2005, 2007). A monograph on Earthquake Source Asymmetry, Structural Media and Rotation Effects was published recently as well by Teisseyre et al. (2006). Measurement of rotational motions has implications for: (1) recovering the complete ground-displacement history from seismometer recordings; (2) further constraining earthquake rupture properties; (3) extracting information about subsurface properties; and (4) providing additional ground motion information to earthquake engineers for seismic design. A special session on Rotational Motions in Seismology was convened by H. Igel, W. H. K. Lee, and M. Todorovska during the 2006 AGU Fall Meeting. The goal of this session was to discuss rotational sensors, observations, modeling, theoretical aspects, and potential applications of rotational ground motions. The session was accompanied by the inauguration of an International Working Group on Rotational Seismology (IWGoRS) 
which aims to promote investigations of all aspects of rotational motions in seismology and their implications for related fields such as earthquake engineering, geodesy, strongmotion seismology, and tectonics, as well as to share experience, data, software, and results in an open Web-based environment.

The primary goal of this article is to make the Earth Science Community aware of the emergence of the field of rotational seismology.

\section{AGU Special Session on Rotational Seismology}

A special session with seven oral presentations and 12 posters was held at the AGU Fall Meeting on 12 December 2006: U. Schreiber and H. Igel presented a paper on Sagnac ring-laser interferometry for the determination of rotations in seismology; V. Graizer a paper on tilts in strong-ground motion; laboratory and field testing of two promising rotational seismometer models were discussed by R. L. Nigbor and others; observations and modeling of broadband rotational ground motions were presented by $\mathrm{H}$. Igel and his colleagues; J. B. Fletcher and P. Spudich reported the seismic rotations and strains at the UPSAR accelerometer array from the 28 September 2004, M6 Parkfield earthquake; rotational ground motions radiated by vibrating structures were discussed by M. I. Todorovska; amplification of ground motion rotations by local geology was reported by L. Godinho and colleagues; modeling of the seismic waves in non-classical media (E. Grekova and others), rotation response of a rigid body under seismic excitation (T. Tobita and S. Sawada), stochastic modeling of rocking seismic ground motion and respective structural load modeling (Z. Zembaty), a synthetic study of source- and basinrelated effects on ground rotational motions ( $\mathrm{H}$. Wang and others), finite-difference numerical simulation of seismic gradiometry (D. F. Aldridge and others); measuring midand near-field rotational ground motions in Taiwan (B. S. Huang and others); observations of rotational motions around vertical and horizontal axes and comparison with translations

(S. Lehndorfer and others); towards a global network of rotation sensors (J. Hautmann and 
others); seismic rotations observed with inertial seismic sensors (R. Pillet and J. Virieux); engineering implications of rotational sensitivity of translational accelerometers (R. L. Boroschek); and a new class of instruments instrument for direct observation of torsional normal mode oscillations of the Earth (R. Cowsik and others).

Some interesting observational results were presented in both the oral and poster sessions. For example, Fletcher and Spudich compared peak velocity to rotation rate from earthquakes recorded at their UPSAR array of accelerometers in Parkfield, California, and found the average for four events to be $2.88 \mathrm{~km} / \mathrm{s}$; they observed rotation rates up to about $200 \mu \mathrm{rad} / \mathrm{s}$ and peak rotations of $\mu \mathrm{rad}$. As shown by Igel et al. (2005), the ratio of acceleration to rotation rate should be $-2 c$, where $c$ is the apparent $S$-wave velocity. This ratio implies a value of $1.44 \mathrm{~km} / \mathrm{s}$ for $c$ is similar to the minimum apparent velocity of $2 \mathrm{~km} / \mathrm{s}$ observed for the mainshock (Fletcher et al., 2006) during the $S$ wave and $4 \mathrm{~s}$ afterwards (body-wave arrivals). Huang and others observed rotational velocities of several hundred earthquakes in Taiwan using a rotational sensor on the surface, directly above a downhole broadband seismometer (100 m depth). Their observed peak rotational velocities are far larger than predicted by Bouchon and Aki (1982) for earthquakes in the near field. If these observations are confirmed, then rotation motions of M5 or larger earthquake at $15 \mathrm{~km}$ away could reach the threshold of structural damage (M. D. Trifunac, pers. comm., 2007).

\section{International Working Group on Rotational Seismology (IWGoRS)}

A luncheon also held at the special session inaugurated the International Working Group on Rotational Seismology (IWGoRS). Creation of the IWGoRS is the result of an earlier workshop on rotational seismology organized by W. H. K. Lee, K. Hudnut, and J. R. Evans of the USGS in February of 2006. That first workshop was organized in response to grass

roots interest and was held at the Menlo Park and Pasadena, California, USGS offices with about 30 participants from numerous institutions participating via teleconferencing and telephone (Evans et al., 2007). 
IWGoRS consists of volunteers and has no official status. Anyone may join either as an "associate member" to receive newsletters and emails, or as an "active member" to lead a new "task force" or join an existing one. Its charter is accessible on the project web site (http://www.rotational-seismology.org).

\section{IWGoRS Website}

IWGoRS uses this Website to promote rotational seismology by sharing ideas, data, software, etc. Website access is free and does not require membership. To start IWGoRS, H. Igel and W. H. K. Lee are serving as "co-organizers". The Working Group has a number of active members leading task forces focusing on the organization of workshops and scientific projects including: testing and verifying rotational sensors, broadband observations with ring laser systems, and developing a field laboratory for rotational motions. The IWGoRS web site also contains presentations and posters from the 2006 AGU special session as well as the earlier workshop; eventually this site will also provide access to rotational data from many sources.

\section{Conclusion}

Rotational seismology is an emergent field previously receiving little attention. The substantial interest in the first workshop and the AGU special session demonstrate that rotational motions are of current interest to a wide range of geophysical disciplines, including strong-motion seismology, exploration geophysics, broadband seismology, earthquake engineering, earthquake physics, seismic instrumentation, seismic hazards, geodesy, and astrophysics, confirming the timeliness of IWGoRS. 
At the IWGoRS inauguration luncheon it became clear that to establish an effective international collaboration within the IWGoRS, a larger workshop was needed to allow sufficient time to discuss the many issues of interest and to draft a research plan for rotational seismology. Thus, the First IWGoRS Workshop will be hosted by the U.S. Geological Survey in Menlo Park, California, on 18-19 September 2007, convened by W. H. K. Lee, M. Çelebi, and M. Todorovska. The Second IWGoRS Workshop will be organized by the European members of the Working Group and is scheduled for 2009.

\section{References}

Aki, K., and P. G. Richards, Quantitative Seismology, $1^{\text {st }}$ edition, W. H. Freeman and Co., San Francisco, California, 1980; $2^{\text {nd }}$ edition, University Science Books, Sausalito, California, 2002.

Bouchon, M., and K. Aki, Strain, tilt, and rotation associated with strong ground motion in the vicinity of earthquake faults, Bull. Seismol. Soc. Am., 72, 1717-1738, 1982.

Evans, J. R., and others, Report of a workshop on rotational ground motion, U.S. Geol. Surv. Open File Rep., 2007-1145, 14 pp., 2007.

Fletcher, J. B., P. Spudich, and L. M. Baker, Rupture propagation of the 2005 Parkfield, California earthquake from observations at the UPSAR, Bull. Seismol. Soc. Am., 96, S129-S142, 2006.

Igel, H., U. Schreiber, A. Flaws, B. Schuberth, A. Velikoseltsev, and A. Cochard, Rotational motions induced by the M8.1 Tokachi-oki earthquake, September 25, 2003, Geophys. Res. Lett., 32, L08309, doi:10.1029/2004GL022336, 2005.

Igel, H., A. Cochard, J. Wassermann, U. Schreiber, A. Velikoseltsev, and N. P. Dinh, Broadband observations of rotational ground motions, Geophys. J. Int., 168(1), 182-197, 2007, doi:10.1111/j.1365-246X.2006.03146.x.

Mallet, R., Great Neapolitan Earthquake of 1857, vol. I and II, Chapman and Hall, London, 1862.

Richter, C. F., Elementary Seismology, W. H. Freeman \& Co., San Francisco, California, 1958.

Teisseyre, R., M. Takeo, and E. Majewski, eds., Earthquake Source Asymmetry, Structural Media and Rotation Effects, Springer Verlag, Berlin, 2006. 